\title{
Factors Affecting Counselling Services in Secondary Schools in Keren Sub-Zone, Anseba Region, Eritrea
}

\author{
Ghebrehiwet Eyasu Andegiorgis \\ Department of Psychology, Faculty of Education, Catholic University of Eastern Africa, \\ P O Box 62157 - 00200, Nairobi, Kenya
}

\begin{abstract}
Implementation of counselling services in schools has its own challenges in Eritrean high schools. This study assessed factors affecting counselling services in secondary schools in Keren Sub-Zone, Anseba Region, Eritrea. The study adopted a mixed method research design across a target population that comprised of 5 schools, 1500 students, 100 teachers, 5 teacher counselors, and 5 head teachers. Systematic sampling, simple random and purposive sampling were used to select schools and the participants of the study. Questionnaires and interview guides were used for data collection. Data gathered through questionnaires was processed using descriptive statistical techniques involving frequencies, percentages and means. Data gathered through interview guide was analyzed and presented using quotes, themes and narrative descriptions. The results showed that there was lack of proper office for counselling services, lack of trained counsellors, less attention given to counselling department, lack of awareness from students and lack of counselling facilities. The study recommended that the ministry of education should provide schools with trained counselors.
\end{abstract}

Keywords: Eritrean counselling, discipline in Eritrea, counsellors, Counselling in Keren, factors affecting counselling.

DOI: $10.7176 / \mathrm{JEP} / 10-31-07$

Publication date: November $30^{\text {th }} 2019$

\section{Introduction and Background}

Research has shown that effective counselling promotes students' academic performance, helps students in career choice and discipline management. However, many schools face many challenges in setting up a practical program of guidance and counselling services. Some of the factors that hinder effective counselling are lack of formal training in counselling, lack of time for guidance and counselling, lack of support given to teacher counselors and lack of resources (Orenge, 2013).

Winthrop and Gough (2012) carried out a study in the UK on factors affecting self-referral to counselling services in workplace. The study used a qualitative methodology to explore why employees are using counselling in the workplace. The study was attended by eleven university employees in northern England who had used their employer's staff counselling service. Two schemes were available to the employer: an internal staff counselling service and an external staff support program (EAP). Each participant used a semi-structured interview and grounded theory techniques to analyze the interviews. The analysis resulted in a psychological help-seeking model being built in the workplace. The main findings indicate that most participants were motivated by their previous positive experiences of similar or other types of mental health services to use the counselling service provided by their employer. Other encouraging factors were: service recommendation by others, a supportive environment, and confidence in the service's confidential ethos. On the other hand, it has been shown that negative preconceptions of psychological help-seeking and a perception of the working environment as unsafe were discouraging factors.

Hui (2016) conducted a study on building an effective guidance services in Hong Kong. Employing a qualitative approach, the study investigated the views of Hong Kong Chinese teachers and students on effective school guidance services. Nineteen teachers and 23 junior secondary students from two secondary schools were interviewed. Findings revealed that all teacher involvement in guidance was essential, as guidance was perceived as having an educational function, in addition to developmental, preventive and remedial functions. Other factors considered crucial in making guidance more effective were teachers' care and concern for students, good teacher student relationships, and the system of management.

Mbongo, Mowes, and Chata (2016) conducted a study with the aim to establish teacher counselors' views on the factors impacting the implementation of guidance and counselling services in the Ohangwena region of Namibia. The study was of a quantitative nature, using a non-experimental design involving an investigation. The study population consisted of teacher counselors at all high schools in the region of Ohangwena. Data were collected using questionnaires which were administered to a sample of twenty-six (26) teacher counselors. Teacher counselors were purposively sampled. The data were analyzed using descriptive statistics using the Statistical Package Social Sciences (SPSS). Based on the study teacher counselors ' findings, inadequate training, high teaching burdens and time constraints, lack of support given to teacher counselors and lack of resources and facilities were considered to be key factors affecting the successful implementation of school guidance and counselling. It was therefore recommended that teacher counselor training be improved in school guidance and 
counselling, reduced workload for teacher counselors, improved resources and guidance and counselling facilities, and to support teacher counselors in order to successfully implement guidance and counselling in schools.

Nyamwaka, Ondima, Nyamwangwe, Ombaba and Magaki (2013) conducted a study on the assessment of implementation levels of guidance and counselling programs in Kenyan secondary schools, a case of Sotik district Bomet County, Kenya. The study used a casual comparative design ex-post facto. Seven schools were randomly selected to provide a sample size of 7 head teachers, 7 teachers guidance and counselling, and 111 students. The study was attended by 16 students from form three and four in each school, bringing the total number of respondents to 125. Questionnaire and schedule of interviews were used as instruments for collecting data. Results from the study findings revealed that as a result of inadequate resources and time, lack of guidance and counselling teacher training, poor student perception of guidance and counselling, and lack of administrative support, counselling programs in Sotik District may not be well implemented. The study therefore recommended the need to properly train guidance and counselling teachers, provide adequate resources for the program, raise awareness among students of the importance of guidance and counselling among and reduce the workload of guidance and counselling teachers to enable them to more effectively perform guidance and counselling tasks.

Alemu (2013) conducted a study evaluating the Guidance and Counselling Services Provisions in East Harerge Zone and Hareri Region, Ethiopia Secondary Schools. The aim of the study was to assess the provision and perceived importance of guidance and counselling. The study used survey design and 336 participants participated in the study. Chi-square, independent sample t-test, Kruskal-Wallis test and percentages were used as data analysis techniques. The result indicated that the school community had poor awareness about the presence of guidance and counselling services at their schools. Male students' utilization of the services was significantly higher than their female counter parts. Fear of asking help was the reason for underutilization of the guidance and counselling services by female students. The schools guidance and counselling programs did not have written plans, specific roles and responsibilities and private counselling rooms. There was loose coordination among principals, teachers, and guidance and counselling programs.

Abraha (2012) conducted a study in primary schools in Keren district Eritrea on factors affecting school community relations. The study was conducted in six primary schools and among their community members. The study sample included six head teachers, 102 teachers, 24 school committee members, 30 parents and 152 pupils randomly selected from grades four and five. All these gave a total of three hundred and fourteen subjects. The instruments for data collection were interviews and questionnaires. The interviews were conducted for all the head teachers, members of school committees and parents. The questionnaires were administered to all the teachers and pupils. The study findings showed that the main factors affecting school community relations in the district were: the community members' low educational standard, the nature of the schools and their locality, limited opportunities provided by the school personnel to involve the community members in school affairs, policies and decisions made by educational authorities, the society's low economic standard, and the personal interest or responsibility in educational activities. The objective of the study was to investigate factors affecting school community relations in primary schools in Keren district Eritrea but not factors affecting counselling on students' discipline. The study was conducted among primary schools while the current study was conducted among high schools. The current study filled the gap by studying the factors affecting counselling services in secondary schools in Keren Sub-zone, Anseba region, Eritrea.

\section{Research Methodology}

The study used convergent parallel mixed method research design. Questionnaires and interview guide were used to collect the data. Questionnaire was given to teachers and students, whereas interview guide was administered to head teachers and teacher counsellors. A sample of 306 students, 20 teachers, 5 head masters, 5 teacher counsellors were used for this study. Systematic sampling, simple random and purposive sampling were used to select schools and the participants. The validity and reliability of the instruments was guaranteed by piloting and Cronbach Alpha technique. Data gathered through questionnaires were processed using descriptive statistical techniques involving frequencies, percentages and means. The results were then presented using tables. Data gathered through interview guides were analyzed and presented using quotes, themes and narrative descriptions. 


\section{Results and Discussion}

3.1 factors affecting counselling services

Table 1 Factors Affecting Counselling Services in Managing Students Discipline According to Students and Teachers Responses

\begin{tabular}{|c|c|c|c|c|c|c|c|c|c|c|c|}
\hline \multicolumn{2}{|l|}{ Factors } & \multicolumn{5}{|c|}{ Students response } & \multicolumn{5}{|c|}{ Teachers response } \\
\hline & & $\mathbf{S A}$ & $\mathbf{A}$ & $\mathbf{U}$ & D & SD & $\mathbf{S A}$ & $\mathbf{A}$ & $\mathbf{U}$ & $\mathbf{D}$ & SD \\
\hline There is enough & $\mathrm{f}$ & 15 & 61 & 29 & 66 & 100 & 2 & 0 & 5 & 4 & 5 \\
\hline $\begin{array}{l}\text { materials } \\
\text { counselling }\end{array}$ & $\%$ & 5.5 & 22.5 & 10.7 & 24.4 & 36.9 & 12.5 & 0 & 31.3 & 25.0 & 31.3 \\
\hline There is Appropriate & $\mathrm{f}$ & 7 & 44 & 32 & 72 & 116 & 1 & 3 & 4 & 4 & 4 \\
\hline $\begin{array}{l}\text { time allocated for } \\
\text { counselling }\end{array}$ & $\%$ & 2.6 & 16.2 & 11.8 & 26.6 & 42.8 & 6.3 & 18.8 & 25.0 & 25.0 & 25.0 \\
\hline Room set aside for & $\mathrm{f}$ & 20 & 53 & 24 & 65 & 109 & 1 & 2 & 5 & 3 & 5 \\
\hline counselling & $\%$ & 7.4 & 19.6 & 8.9 & 24.0 & 40.2 & 6.3 & 12.5 & 31.3 & 18.8 & 31.3 \\
\hline There is a qualified & $\mathrm{f}$ & 17 & 45 & 57 & 51 & 101 & 2 & 0 & 3 & 6 & 5 \\
\hline counsellor & $\%$ & 6.3 & 16.6 & 21.0 & 18.8 & 37.3 & 12.5 & 0 & 18.8 & 37.5 & 31.3 \\
\hline Counsellors & $\mathrm{f}$ & 46 & 67 & 41 & 36 & 81 & 1 & 4 & 5 & 3 & 3 \\
\hline $\begin{array}{l}\text { friendly } \\
\text { approachable }\end{array}$ & $\%$ & 17.0 & 24.7 & 15.1 & 13.3 & 29.9 & 6.3 & 25.0 & 31.3 & 18.8 & 18.8 \\
\hline Counselling is part of & $\mathrm{f}$ & 30 & 56 & 46 & 65 & 74 & 1 & 1 & 5 & 3 & 6 \\
\hline school timetable & $\%$ & 11.1 & 20.7 & 17.0 & 24.0 & 27.3 & 6.3 & 6.3 & 31.3 & 18.8 & 37.5 \\
\hline Lack of awareness & $\mathrm{f}$ & 135 & 37 & 23 & 43 & 33 & 3 & 5 & 4 & 3 & 1 \\
\hline about counselling & $\%$ & 49.8 & 13.7 & 8.5 & 15.9 & 12.2 & 18.8 & 31.3 & 25.0 & 18.8 & 6.3 \\
\hline
\end{tabular}

Note 1: f: frequency, \%: percentage, SA: Strongly Agree, A: Agree, U: undecided, D: disagree, SD: strongly disagree

The study findings from Table 1 showed that $36.9 \%$ of student respondents and $31.3 \%$ of teacher respondents strongly disagreed that the schools have enough counselling materials. Moreover, a higher number of students, $42.8 \%$ and a quarter, $25 \%$ of teachers strongly disagreed that appropriate time was allocated for counselling services. However, $25 \%$ of teachers were undecided whether there was appropriate time allocated for counselling in schools. The findings clearly show that the counselling service in Keren secondary schools lack basic materials to function well. Therefore, because of such scarce resource counselling service is not assisting student in curbing indiscipline. The results of the current study are similar to Mbongo, Mowes and Chata (2016) findings which was carried out in Namibia. The study revealed that lack of support given to teacher counsellors and lack of resources and facilities as factors impacting the successful implementation of counselling services in managing students' discipline.

A higher proportion, $24 \%$ and $40.2 \%$ of the student respondents disagreed and strongly disagreed that a room was set aside for counselling services in schools respectively. Only small percentage, $7.4 \%$, of the students strongly agreed that there was room set for counselling. Moreover, nearly a third, 31.3\%, of teachers were undecided and strongly disagreed that there was a room set for counselling. In addition, counsellor 3 reported that "In my school we lack basic resources for counselling service, such as files, desks, seats and proper counselling office. Currently I counsel my students in student affairs office and in open areas under a shade." The results clearly show that such factors affect or impede counselling services from being fully operational and helping to curb the discipline of the student.

A high number of students, $37.8 \%$ and $37.5 \%$ of teachers strongly disagreed that the schools had trained or qualified counsellors. Only $6.3 \%$ of students and $12.5 \%$ of teachers strongly agreed that there was a qualified counsellor in their schools. It apparent that all those working as counsellor in Keren secondary schools are untrained and unqualified. Since, they are untrained the service they give is not to the standard and fail to help students in discipline matters in the school. Such results corresponds to the findings of Kamore and Tiego (2015) in their study done in Kenya revealed that guidance and counselling departments were ineffective in enhancing school discipline, because guidance and counselling teachers were inadequately trained, motivated and faced with many challenges such as lack of facilities, offices for counselling, lack of time and enough recourses.

A good number of students, $29.9 \%$, strongly disagreed that counsellors were friendly and approachable. The finding makes it evident that counsellor were unfriendly and unwelcoming. Students don't use counselling service when the condition is not good. Only $17 \%$ of the students strongly agreed that counsellors were friendly and approachable. However, $31.3 \%$ of teachers were undecided whether counsellors were friendly and approachable. A higher proportion of the students, $27.3 \%$ and $37.5 \%$ teachers strongly disagreed that counselling was part of school timetable. Moreover, $49.8 \%$ of students and $31.3 \%$ of teachers strongly agreed and agreed that there was lack of awareness about counselling services in schools respectively. This finding is in line with the findings of Odhiambo (2016) who found out that most teacher counsellors were not trained, the counselling departments 
lacked essential resources, and there was lack of awareness about counselling, lack of confidentiality and unfriendly counsellors.

From the qualitative analysis both head teachers and teacher counsellors said the main factors that affect counselling services were lack of proper office for counselling services, lack of trained counsellors, not knowing students background, no counselling materials at all, less attention from school management to counselling department, lack of awareness both from students and teachers about counselling services, counselling offices being run by unqualified personnel such as the student affairs and discipline masters, students feeling shy, and overall lack of availability of resources for counselling services. Students also reported that there was lack of follow up by teacher counsellors, students not trusting counsellors, carelessness by students, teachers not understanding students' problems and mismanagement of counselling office. Such factors affect counselling services greatly and affects its effectiveness in managing students' discipline.

\subsection{Importance of Counselling Services to Students}

The following graph shows how much importance students put to counselling services.

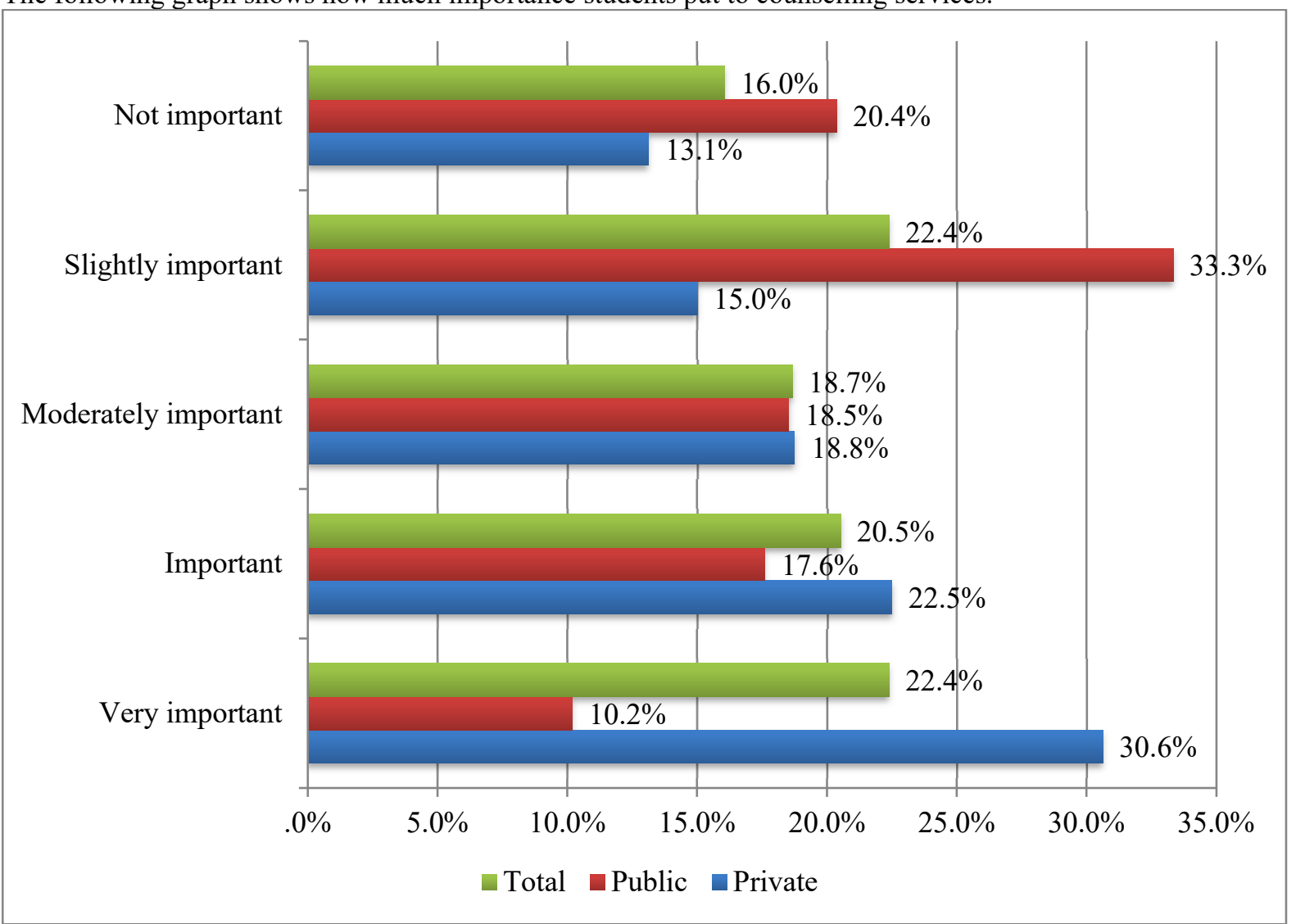

Figure 1. Importance of counselling according to students response

In reference to Figure 1, the findings from the student respondents show mixed perceptions of the importance of attending counselling, with some feeling in between "very important" to "not important." The findings further showed a variance of preferences between private and public schools. A good number, $30.6 \%$ from private schools rated counselling as very important compared to only $10 \%$ of public schools. A higher number, 20.4\%, of public school students rated attending counselling as not important.

Generally, private school students more valued the importance of counselling services as compared to public school students. As indicated Figure 8 student respondents especially from public schools did not consider counselling service as important for guiding students' discipline. This lack of understanding about the importance of counselling may hinder the students from attending such counselling services. The results show that students attach less importance to counselling service and it affects the use of counselling service as whole by students.

\section{Conclusion}

The study found that availability of enough materials for counselling sessions, specific allocation of rooms and time for counselling, lack of trained or qualified counselors, lack of awareness and understanding of students about counselling service were the factors affecting the counselling service in managing students' discipline. 
The study revealed that high number of students and teachers strongly disagreed that their school had enough counselling materials; appropriate time allocated for counselling, counselling rooms and qualified counselors. Other factors were lack of awareness about counselling services, students consider less importance of counselling services and unfriendly and unapproachable counselors.

Head teachers and teacher counsellors reported that the main factors that affect counselling services were lack of proper office for counselling services, lack of trained counsellors, not knowing students background, no counselling materials at all, less attention from school management to counselling department, lack of awareness both from students and teachers about counselling services, counselling offices being run by unqualified personnel such as the student affairs and discipline masters, students feeling shy, and overall lack of availability of resources for counselling services.

\section{Recommendations}

Ministry of education should come out with clear guide and policy on how to implement counselling services in schools. The current study make it very clear that no school has a separate room for counselling service, which makes it very difficult for teacher counsellors to provide counselling services to students. The physical structure for counselling should be of quality standard and that assures high level of confidentiality in order to stimulate students' interest towards counselling services from students. The ministry of education should provide to each school a qualified and trained counsellor.

\section{References}

Abraha, A.T. (2012). Factors affecting school-community relations in primary schools in Eritrea: A case study of Keren District. Unpublished Master's thesis.

Alemu, Y. (2013). Assessment of the provision of Guidance and counselling Services in Secondary schools of East Harerge Zone and Hereri region, Ethiopia. Middle Eastern \& African Journal of Educational Research, $6(2), 28-37$

Hui, E.K.P. (2016). Building an effective guidance and counselling services in Hong Kong. Asia Pacific Journal of Education, 9(1), 78-88.

Kamore, S.K. \& Tiego, P.M. (2015). What hinders guidance and counselling effectiveness in enhancing discipline in high schools in Muranga County, Kenya? International Journal of Science and Research, 6(4), 796-801.

Mbongo, E., Mowes, A., \& Chata, C. (2016). Factors impacting the implementation of guidance and counselling services in secondary schools in the Ohangwena Region of Namibia. International journal for Innovation Education and research, 4(5), 11-25.

Nyamwaka, E., Ondima, Nyamwange, Ombaba \& Magaki, E. (2013). Assessment of implementation levels of guidance and counselling programs in Kenyan secondary schools: A case of Sotik District, Bomet County, Kenya. Journal of Education and Practice, 4(3), 65-78.

Odhiambo, B.A. (2016). Factors influencing provision of guidance and counselling services in mixed day secondary schools, Nyakach District, Kisumu County, Kenya. Journal of Education and Practice, 4(3), 6578.

Orange, E. (2013). The status of career guidance and counselling programs for students in public secondary school in Nairobi province. Research paper Kenyatta University.

Winthrop, A. \& Gough, B. (2012). Factors affecting self-referral to counselling services in work place: a qualitative study. British Journal of Guidance and Counselling, 36(3), 257-276. 